\title{
Regularity of distribution of precipitation at the airdromes of Azerbaijan Republic
}

\author{
N. Huseynov ${ }^{1,2}$ and B. Malikov ${ }^{1,2}$ \\ ${ }^{1}$ Azerairnavigation ATM, Int'1. Airport Heydar Aliyev/Baku, Azerbaijan \\ ${ }^{2}$ National Academy of Aviation, Baku, Azerbaijan
}

Received: 21 October 2008 - Revised: 4 March 2009 - Accepted: 5 March 2009 - Published: 10 March 2009

\begin{abstract}
A study of the regularity of precipitation distribution at the airdromes of Azerbaijan Republic was carried out for the purpose of defining the basic parameters of the climatic peculiarity that have an impact on the activities of civil aviation. For calculation of the key parameters, mathematical analysis methods are applied on the long-term statistical data.
\end{abstract}

\section{Introduction and data}

For the study of the level of impact of the climatic factors on aviation maintenance, one of the basic issues that should be investigated is the distribution of precipitation at the airdromes. Precipitation is an important climatic variable and has special value in working out aviation-climate relationships of the airdromes.

For the purpose of studying the nature of precipitation distribution at the airdromes of Azerbaijan Republic, the monthly and annual amounts of raingauge measured precipitation within the period 1955-1999 were utilized. The data were collected at the following airdromes: Baku/Heydar Aliyev, Nakhchivan, Ganja, Yevlakh and Lenkoran.

\section{Results}

Table 1 shows that the smallest amount of precipitation was observed at Baku and Nakhchivan, while the largest was at Lenkoran. Precipitation at the Nakhchivan airdrome results mainly during intrusions of cold air masses. At the Nakhchivan airdrome the annual average is $271 \mathrm{~mm}$. According to the basic seasonal feature, the maximum precipitation occurs during the cold half of the year.

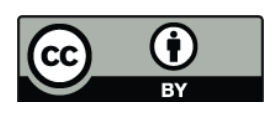

Correspondence to: B. Malikov (melikov@azans.az)
Because of the mountains near Nakhchivan, a minimuml amount of precipitation occurs at the airdrome. This area is open to the dry air masses flowing in from semi-deserts. For the period of review, the mean long-term value of the annual amount of precipitation at the airdrome "Baku" was $272 \mathrm{~mm}$. The airdrome is located in a semiarid zone. The minimum annual amount of precipitation $(131 \mathrm{~mm})$ was observed in 1983, and the maximum (434 mm) - in 1969. The amount of precipitation essentially less than the norm was observed in 1960, 1986, 1989 and 1998. On the contrary, the largest amount of all precipitation was observed in 1963, 1973, 1982 and 1999.

Furthermore, the norm of the annual amount of precipitation was researched for the period 1961-1990 as recommended by the World Meteorological Organization. Within this period the amount of precipitation, in comparison with the period of 1955-1999 (272 mm) changed insignificantly. It rose to $277 \mathrm{~mm}$. Within the examined period the amount of precipitation increased for $5 \mathrm{~mm}$ only.

For the last 5 years of the observation period (1995-1999), the annual amount of precipitation in comparison with the period of 1955-1999 decreased by $22 \mathrm{~mm}$ and was $255 \mathrm{~mm}$.

The calculation of two parameters of the annual amount of precipitation with a temporary variability was carried out with the mean quadratic deviation $(\sigma)$ and factor of a variation $\left(C_{v}\right)$. These parameters were calculated with:

$\sigma=\sqrt{\frac{\sum_{i}^{n}\left(x_{i}-\bar{x}\right)^{2}}{n}}$

$$
C_{v}=\sqrt{\frac{\sum_{i}^{n}\left(k_{i}-1\right)^{2}}{n}}
$$

Published by Copernicus Publications on behalf of the European Geosciences Union. 
Table 1. Long-term mean values of monthly and annual precipitation amounts (in $\mathrm{mm}$ ).

\begin{tabular}{llllllllllllll}
\hline Airdrome & Jan & Feb & Mar & Apr & May & Jun & Jul & Aug & Sep & Oct & Nov & Dec & Total \\
\hline Baku & 28 & 24 & 27 & 24 & 21 & 9 & 2 & 8 & 22 & 40 & 38 & 34 & 277 \\
Nakhchivan & 25 & 23 & 33 & 40 & 40 & 23 & 8 & 6 & 8 & 20 & 26 & 19 & 271 \\
Ganja & 14 & 15 & 20 & 30 & 41 & 39 & 25 & 16 & 24 & 24 & 21 & 13 & 282 \\
Yevlax & 22 & 27 & 37 & 31 & 35 & 31 & 15 & 13 & 25 & 34 & 31 & 22 & 323 \\
Lenkoran & 87 & 87 & 128 & 71 & 41 & 40 & 42 & 84 & 235 & 276 & 201 & 110 & 1402 \\
\hline
\end{tabular}

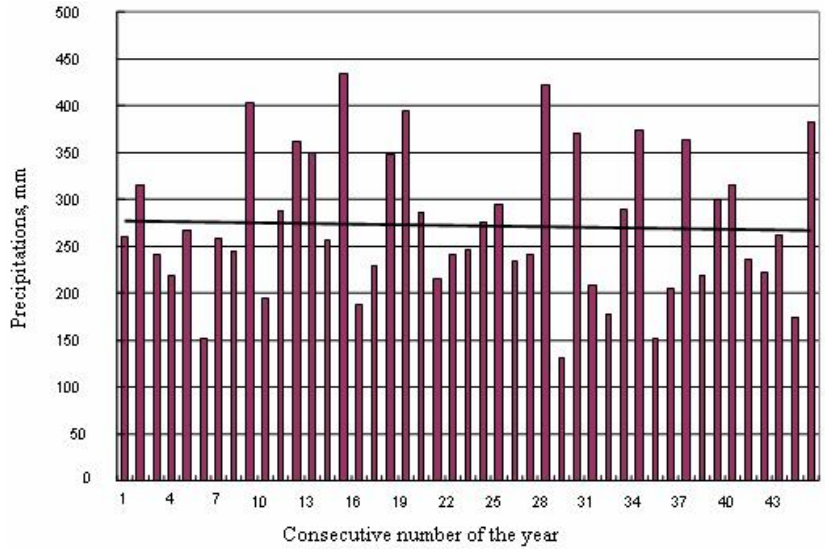

Fig. 1. Long-term trend of annual amounts of precipitation.

$\begin{array}{ll}x_{i} & \text { annual precipitation } \\ \bar{x} & \text { the norm of precipitation } \\ n & \text { the period of observation } \\ k_{i} & \text { ratio }\end{array}$

Here, for the whole reviewed period $\sigma=76.5 \mathrm{~mm}$, $C_{y}=0.28$, and for the period of $1961-1990-\sigma=82.4 \mathrm{~mm}$ and $C_{y}=0.30$.

Thus, it is concluded that the values of these statistical parameters for the analyzed periods have not essentially varied.

An analysis of a long-term trend of the annual sums of precipitation was carried out. For defining the directional deviations in long-term precipitation the method of a linear trend was used. The trend shown through a long-term course of measuring the annual amounts of precipitation is shown in Fig. 1.

The following equation was used to calculate the linear trend:

$X=-0.2433 \cdot N+277$

\section{$X \quad$ Annual precipitation amount}

$N$ Consecutive number in line

According to Fig. 1 and Eq. (3), the negative trend for long-term trend of annual amounts of precipitation is defined. However, a non-significant statistical difference is inferred by this reduction of precipitation, since $R^{2}=0.0017$.
Table 2. Mean values, mean square deviation $(\sigma)$, coefficient of variation $\left(C_{v}\right)$ of seasonal precipitation sum for various observation periods.

\begin{tabular}{|c|c|c|c|c|c|}
\hline Period & Parameter & Winter & Spring & Summer & Autumn \\
\hline \multirow[t]{3}{*}{ 1955-1999 } & Mean value & 84.6 & 64.6 & 17.8 & 103.8 \\
\hline & $\sigma$ & 38.1 & 36.8 & 15.4 & 53.2 \\
\hline & $C_{v}$ & 0.45 & 0.57 & 0.87 & 0.51 \\
\hline \multirow[t]{3}{*}{ 1961-1990 } & Mean value & 85.6 & 71.6 & 18.7 & 100.4 \\
\hline & $\sigma$ & 41.0 & 39.1 & 17.4 & 50.5 \\
\hline & $C_{v}$ & 0.48 & 0.55 & 0.93 & 0.50 \\
\hline 1995-1999 & Mean value & 84.8 & 31.6 & 13.8 & 130.0 \\
\hline
\end{tabular}

The intra-annual distribution of precipitation is considered in two ways: by calendar months and by seasons of the year.

Mean annual rainfall is defined specifically for each month of the whole observation period.

The analysis of the long-term data shows, that intra-annual distribution of precipitation at the airdrome at Baku is very irregular. In the summer period, especially in July, the minimum precipitation was observed. For some years (1956, $1962,1971,1980,1995$, etc.) in July precipitation was not observed at all. In 1978, even in September, no precipitation was observed.

Within the long-term period, the maximum precipitation was registered in November. However, in 1983 the maximum was registered in September, and in 1969, in January.

At the airdrome of Nakhchivan, within the annual trend of precipitation, the basic maximum was registered in spring (April-May) and the secondary was registered in autumn. The basic minimum precipitation was registered in summer, and in the beginning of winter. In some years, the significant deviation of the monthly and annual sum of precipitation compared with the average over the long-term was registered. The cause was attributed to the character of the development and intensity of atmospheric processes. In some cases, the one month amount of precipitation exceeded the monthly long-term norm by 2-3 times. Thus, in July of 1997 at the airdrome of Nakhchivan, $62 \mathrm{~mm}$ of precipitation were registered. This is nine times the climatic norm. The variability of the amount of precipitation is great. 
Table 3. Mean values of maximum daily amount of precipitation $(X)$, their factors of a variation $\left(C_{v}\right)$ and asymmetry $\left(C_{S}\right)$.

\begin{tabular}{llllllllllllll}
\hline \multirow{2}{*}{ Parameter } & \multirow{2}{*}{ Jan } & Feb & Mar & Apr & May & Jun & Jul & Aug & Sep & Oct & Nov & Dec & Year \\
\hline X, mm & 9 & 7 & 10 & 11 & 7 & 5 & 3 & 5 & 9 & 12 & 13 & 10 & 13 \\
$C_{v}$ & 0.81 & 0.68 & 0.91 & 1.01 & 1.31 & 1.12 & 1.40 & 1.56 & 0.94 & 0.87 & 0.83 & 0.68 & 0.47 \\
$C_{S}$ & 2.05 & 0.83 & 1.65 & 2.27 & 3.45 & 2.31 & 2.74 & 2.51 & 1.39 & 2.06 & 2.05 & 1.04 & 1.37 \\
\hline
\end{tabular}

The mean values of the precipitation for each month were calculated for the period of 1961-1990 and 1995-1999 (Table 2).

In Table 2, the mean quadratic deviation and coefficient of monthly variation of precipitation are shown. The range of value $C_{v}$ changes from (February, 0.64) to (August, 1.53). As a whole, the minimum values $C_{v}$ were registered in the winter months, and the maximum in the summer months, as well as in May.

The seasonal distribution of precipitation was also irregular. The maximum amount of precipitation fell in autumn (September, October, and November) at $104 \mathrm{~mm}$ (38.3\% of annual). As it was already shown in Table 2, the minimum amount of precipitation was registered in summer $-18 \mathrm{~mm}$ (6.5\%). In the winter months, the amount of precipitation was greater, than in the spring months. The average longterm value of precipitation in a winter season was $85 \mathrm{~mm}$ $(31.2 \%)$, and for a spring season $-65 \mathrm{~mm}(24.0 \%)$.

The distribution of the annual amount of precipitation during the seasons of year for the period of 1961-1990 is similar to the dates shown in Table 2 .

For the last 5 years (1995-1999), in comparison with the long-term period, the amount of precipitation for the spring season decreased by $50 \%$, and for summer season - by $24 \%$. In autumn, on the contrary, the amount of precipitation increased by $25 \%$. Winter precipitation barely changed.

In Table 2, the long-term deviation and variation for all seasons of the year, during all observation periods and during 1961-1990 are also shown. Apparently, the maximum value of the factor of variation is typical for the summer season $\left(C_{v}=0.87\right)$, and the minimum value, for the winter season $\left(C_{v}=0.45\right)$. For the spring and autumn seasons, the values are 0.57 and 0.51 , respectively.

For the definition of trends in a long-term period of the seasonal sums of precipitation, the method of linear trend was adopted. For this purpose, the middle months of each season were chosen: 4 January, 5 April, 6 July and 7 October.

$$
\begin{aligned}
& X=-0.1774 \cdot N+30, \\
& X=-0.2914 \cdot N+28, \\
& X=-0.1095 \cdot N+3, \\
& X=-0.195 \cdot N+39
\end{aligned}
$$

For April and January, the negative linear trend is defined i.e. in a long-term period, the amount of precipitation decreased; $R^{2}$ for April is 0.0436 and for January is 0.0142. The trend for October is statistically insignificant $\left(R^{2}=0.0068\right)$; for July the trend is not registered at all.

In a long-term period, only $7 \%$ of the total amount of precipitation within one year fell as snow and snow grouts, $12 \%$ - as mixed (sleet, snow with rain), and $81 \%$ - as rain. The largest amount of firm precipitation was observed in February (26\%), and mixed was shown in March (39\%). In some years, snow with rain can be observed in the first half of April. From May till October, precipitation falls only as rain. In November and December, rain is $80 \%$ of all precipitation.

In Table 3, the mean values of maximum daily amount of precipitation, their factors of a variation and asymmetry are shown. The analysis of the table shows that the maximum values of the average maximum daily amount of precipitation was registered in October through to November (12$13 \mathrm{~mm}$ ) and March and April (10-11 mm), and the minimum was shown in June-August $(3-5 \mathrm{~mm})$. The maximal values of factor of a variation $\left(C_{v}\right)$ are typical for daily precipitation during April through to August (1.01-1.56) and the minimum values of $C_{v}$ are 0.68 for February and December. The maximal values of the factor of asymmetry for April through to August 2.31-3.45, and minimum for February and December: 0.83 and 1.04 accordingly.

The duration of precipitation is one of the major characteristics of atmospheric precipitation. During autumn-winter season the rainy periods have endure from 1 to 3 days. Longer rainy periods are seldom observed. Rains falling in spring and in summer, as a rule, have a short-term showerlike character.

The average duration of annual precipitation is $618 \mathrm{~h}$ for Baku, with a maximum in January ( $95 \mathrm{~h}$ ) and a minimum in July and August (7-8 h). Total duration of precipitation for the warm period (March through to October) is 2.5 times less, than for the cold period. At the same time, the total amount of precipitation in summer was $11 \%$ less than in the winter period.

For every calendar month the value of the maximum duration of precipitation exceeds the corresponding mean values by $2-3$ times.

The maximum duration of precipitation at the airports Nakhchivan and Ganja was observed during the autumn and 
winter period (51-56 h); in Lenkoran during the spring and summer periods $(64-68 \mathrm{~h})$; in Yevlakh during the autumn and winter period $(42-49 \mathrm{~h})$. As a whole, the annual trend of the duration of precipitation correlates well with the annual trend of their amount.

\section{Conclusions}

As a result of this statistical analysis, the following characteristics of precipitation at the airdromes of the Azerbaijan Republic were determined:

1) Mean values of the monthly and annual sums;

2) Seasonal description of precipitation;

3) Norms of annual amounts for the periods 1955-1999, 1961-1990 and 1995-1999;

4) Parameters of time variability of annual, monthly and seasonal amounts;

5) Long-term trend of the annual sums;

6) The ratio of precipitation types;

7) Seasonal duration and annual trend of duration.

Edited by: S. C. Michaelides

Reviewed by: two anonymous referees

\section{References}

Brooks, C. E. P. and Carruthers, N.: Handbook of statistical methods in meteorology, H.M.S.O., London, 1953.

Huseynov, N.: Application of Probabilistic Logic and the Theory of Statistical Solutions for the Alternative Forecast of Thunderstorms, Proceedings of National Academy of Aviation, Azerbaijan, Baku, 5, 20-23, 2003.

Pashayev, A. and Huseynov, N.: Climatic Characteristic of Airport Heydar Aliev, 68-84, 2007.

Pashayev, A. and Huseynov, N.: Climatic Characteristic of Nakhchivan Airport, 47-49, 2005.

Pashayev, A. and Huseynov, N.: Climatic Characteristic of Airport Ganja, 70-75, 2003.

Panofsky, H. and Brier, G.: Some Applications of Statistics to Meteorology, 17-21, 1958. 